\title{
Microstructure evolution of tailing-based nanocrystalline glass-ceramics under microwave irradiation
}

Qingwei Bai ( $\sim$ abcqingwei@163.com )

Inner Mongolia University of Science and Technology https://orcid.org/0000-0002-9838-2072

Ming Wen

Inner Mongolia University of Science and Technology

\section{Research Article}

Keywords: microwave radiation, nanocrystalline glass-ceramics, flexural strength, thermal stability, microstructure differences, Nucleation

Posted Date: June 19th, 2020

DOl: https://doi.org/10.21203/rs.3.rs-30967/v2

License: (c) (i) This work is licensed under a Creative Commons Attribution 4.0 International License.

Read Full License 
The authors have withdrawn this preprint from Research Square 